\title{
Liquefaction Estimation and Hazard Evaluation Criteria of Sand Soil Foundation of Horizontal Ground
}

\author{
Zecheng Chi ${ }^{a}$, ZhangJun Dai ${ }^{b}$, Shanxiong Chen, Jian Li, Ruijun Song
}

State Key Laboratory of Geomechanics and Geotechnical Engineering, Institute of Rock and Soil Mechanics, Chinese Academy of Sciences, Wuhan 430071, China

a398449801@qq.com, b527353357@qq.com

Key words: sand liquefaction; liquefaction estimation; hazard evaluation; evaluation criteria.

\begin{abstract}
Sand liquefaction is a common seismic hazard of foundation. In order to investigate the hazard evaluation criteria of liquefaction of sand soil foundation, a research was made to study different methods of discriminating sand liquefaction with the reference of the results of recent related studies in this area. Through comparisons, the study finds out that the standard penetration test (SPT) is a relative reliable method to determine liquefaction. Moreover, based on the related researches about the estimation and hazard evaluation of sand liquefaction, the procedures and standards of the liquefaction hazard evaluation of sand soil foundation of horizontal ground have been put forward at the end through this study.
\end{abstract}

\section{Introduction:}

The experience of seismic hazard shows that sand liquefaction is a common seismic hazard of foundation. And foundation failure is one of the main forms of ground damage caused by foundation liquefaction. Therefore, a research and analysis about foundation failure caused by liquefaction should be made when the building is based on sand soil foundation. Furthermore, the safety of the foundation also needs to be investigated ${ }^{[1]}$.

Considering from the practical aspect of engineering, it is crucial to judge whether the soil layer liquefaction happens and the impacts of liquefaction on superstructure, which are two closely, related questions. Moreover, in the evaluation of construction site, the latter is more important than the former. However, due to the complexity of foundation liquefaction, the study of its influence on superstructure is still imperfect which needs further research. In addition, there still exists a gap about the research on the foundation security identification under seism action.

\section{Sand Soil Liquefaction Estimation}

Preliminary Estimation of Sand Soil Liquefaction. The criteria or standards of liquefaction estimation based on the relevant regulations in China are roughly the same. Basically, four 
standards are adopted to estimate sand liquefaction which are the percentage of clay content, the geologic time, the depth of ground water and the thickness of overlying the liquefaction soil layer. In the following, the "Code for seismic design of building (GB50011-2010)"

1) If the geologic time is the Late Pleistocene of the Quaternary or its former time, the seismic intensity of 7,8 could be judged to be non liquefied.

2) The percentage of clay particles (particle size less than $0.005 \mathrm{~mm}$ ) percentage, the seismic intensity of 7,8 and 9, respectively, is not less than 10,13 and 16, can be judged as non liquefied soil. The clay content percentage of silt (Note: The clay content in liquefaction estimation is measured through using sodium hexametaphoshpate (SHMP) as dispersant. If other methods are applied, corresponding conversion should be used according to related regulations).

3) For the building constructed on the shallow buried natural foundation, there is no need to consider the impacts of liquefaction when the thickness of overlying non-liquefied soil layer and the depth of underground water are in accordance with the one of the following conditions:

$$
\begin{aligned}
d_{u} & >d_{0}+d_{b}-2 \\
d_{w} & >d_{0}+d_{b}-3 \\
d_{u}+d_{w} & >1.5 d_{0}+2 d_{b}-4.5
\end{aligned}
$$

Further Estimation of Sand Soil Liquefaction and Comparison of Different Methods. When the possibility of liquefaction is ensured through the preliminary liquefaction estimation, then a further estimation is necessary. As a result, most of the sand soil liquefaction estimations are made based on the test data on the real construction site. These liquefaction estimations are made mainly through these methods such as standard penetration test (SPT), static cone penetration test (CPT), shear wave velocity method (VS) ${ }^{[2]}$. Among these approaches, standard penetration test (SPT) has been developed rather more maturely as the method to do further liquefaction estimation. Numerous researches, test data and construction experience have proved that SPT has been widely accepted way of liquefaction estimation in engineering field all over the world.

Static cone penetration test (CPT) and shear wave velocity method (VS) of liquefaction estimation are developed on the base of standard penetration test (SPT) ${ }^{[3]}$. However, both of them have their own defects. For CPT, the biggest disadvantage is the lack of effective data. Moreover, the type of the soil can only be deduced by CPT. As for VS, it is still under research. The number of the research about field data of liquefaction though VS is far from satisfactory. Therefore, there still exists discussion in the evaluation of VS. In the use of VS, the susceptibility of liquefaction resistance to shear wave velocity is commonly thought as the key element which influences the accuracy of VS. Studies find out that when the shear wave velocity increases by $40 \%$, the liquefaction resistance almost increases to 2 times the original value. The small difference in shear 
wave velocity could lead to the significant change of liquefaction resistance as a result of which makes VS less precise to make liquefaction estimation.

To sum up, it is more accurate to use standard penetration test (SPT) to make liquefaction estimation which is also widely accepted and recommended in construction field in the whole world. Furthermore, the accuracy of sand liquefaction estimation will be improved when more data is used in standard penetration test.

\section{Calculation Method of Seismic Subsidence of Liquefied Foundation}

Seismic subsidence of foundation is one of the important reasons which result in the damage of constructions. Therefore, the seismic resistance performance of foundation has drawn more and more concerns from the field of engineering.

1) Simplified Method ${ }^{[4]}$. Simplified method could better reflect the real situation of seismic demage. Additionally, the theory is easy to understand. The procedure is easy to manipulate. The amount calculation is small.

2) Modulus Soften Model ${ }^{[5]}$. Liquefaction is one manifestations of soften. Saturated sands hardly drain off water during the period of the short earthquake. It is soften gradually due to the seismic effect of earthquake which finally result in seismic subsidence. The process of the softening of saturated sands is the process of the increased level of seismic pore water pressure in the layer of saturated sand until sand and water gushing out. Obviously, before fully liquefaction of saturated sand is reached, softening liquefaction seismic subsidence plays the main role.

3) Finite Element Method ${ }^{[6]}$. In finite element method, a variety of elements such as features of the liquefied layer, non-liquefied layer, the upper building and. Under certain situations, the quantity of seismic subsidence calculated through finite element method not only reflects the influence of ,but also considers the of liquefied layer. Thus, it is more suitable to be used in seismic hazard analysis of important construtions.

\section{Hazard Evaluation of Liquefaction}

The methods of liquefaction estimation illustrated above can only estimate liquefaction of certain saturated soil layer under certain dynamic load. However, it does not necessarily lead to risks on the existence and the use of the construction even though the liquefaction is estimated in the soil layer. The high dangerous level of liquefaction does not always mean the direct measures should be taken on the liquefied layer. Therefore, from the aspect of the safety and economy of engineering, the effects of liquefaction have more direct and closer relation with engineering. Then it is necessary to 
do the hazard evaluation of the layer of foundation. The detailed methods of hazard evaluation of liquefaction are explained as following.

\section{Conclusion}

1) When the presence of saturated sandy soil and saturated silt locate under the ground, except 6 degrees, should carry on the liquefaction discrimination. Seismic fortification intensity is 6 degrees, don't consider the effect of liquefaction。

2) The liquefaction hazard evaluation refers to without seismic design and reinforcement of existing housing and foundation, under the seismic action may damage caused by liquefaction. Every discriminant for liquefiable soil layer, can according to liquefaction index or calculating vibration value of liquid level and the degree of harm, the specific evaluation criteria detailed in table 2.12.

Table 1 level in liquefied foundation affect the grading standard

\begin{tabular}{|c|c|c|c|c|}
\hline $\begin{array}{c}\text { Liquid } \\
\text { level/liquefaction } \\
\text { hazard level }\end{array}$ & I & II & III & IV \\
\hline Influence degree & Not liquefied & slight & medium & serious \\
\hline Liquefaction index IlE & $/$ & $0<\mathrm{IlE} \leq 6$ & $6<\mathrm{IlE} \leq 18$ & IlE $>18$ \\
\hline $\begin{array}{c}\text { The average } \\
\text { liquefaction settlement } \\
\text { value/cm }\end{array}$ & $<4$ & $4-8$ & $8-20$ & $>20$ \\
\hline
\end{tabular}

\section{References}

[1] Zhang Chongwen Zhao Jianming, BiZhengGen. Powder soil liquefaction analysis [J]. Journal of tianjin university, 1997, (7) : 56-57.

[2] 《Geotechnical engineering geological specification》(GB50021-2001).

[3] Cheng Guoyong. Evaluation of the shear wave velocity of saturated sand liquefaction resistance research. Journal of China civil aviation college, 2006, 24 (6).

[4] SILVER M L, SEED HB. Volume changes in sands during cyclic loading[J]. Journal of the Soil Mechanics and Foundations Division, ASCE, 1971, 97(9): 1171-1182.

[5] Xie Junfei Shi Zhaoji, YuShouSong, et al. Liquefaction hazard analysis [J]. Earthquake engineering and engineering vibration, 1988, 8 (1) : 61-77.

[6] Qing-sheng Chen, Xiong Hao guang-yun gao. Based on the nonlinear fatigue damage cumulative model $\mathrm{R}$ - $\mathrm{N}$ of sandy soil settlement calculation method. Journal of geotechnical engineering. 2013, 35 (12) : 2203-2210 